\title{
A randomised controlled trial of the effect of laryngeal mask airway manometry on postoperative sore throat in spontaneously breathing adult patients presenting for surgery at a university teaching hospital
}

\author{
David Waruingi, Vitalis Mung'ayi, Ednah Gisore, Sikolia Wanyonyi
}

Department of Anaesthesia, Aga Khan University, East Africa.

1.David Waruingi: Phone: + 25420366 2158, Email: david.waruingi@aku.edu

2. Vitalis Mung'ayi: Phone: +254 20366 2175, Email: vitalis.mung'ayi@aku.edu

3. Ednah Gisore: Phone: + 25420366 2175, Email: ednah.gisore@aku.edu

4. Sikolia Wanyonyi: Phone: + 25420366 2158, Email: sikolia.wanyonyi@aku.edu

\begin{abstract}
Background: Laryngeal mask airways (LMAs) are widely used in anaesthesia and are considered to be generally safe. Postoperative sore throat (POST) is a frequent complication following LMA use and can be very distressing to patients. The use of an LMA cuff pressure of between 30 and $32 \mathrm{~cm}$ of $\mathrm{H}_{2} 0$ in alleviating post-operative sore throat has not been investigated.

Objective: To compare the occurrence of POST between the intervention group in which LMA cuff pressures were adjusted to $30-32 \mathrm{~cm}$ of $\mathrm{H}_{2} 0$ and the control group in which only monitoring of LMA cuff pressures was done, to compare the severity of POST between the two study groups and to compare the LMA cuff pressures between the two study groups.

Methods: Eighty consenting adult patients scheduled to receive general anaesthesia with use of an LMA were randomized into two groups of 40 patients each. Intervention group: LMA airway cuff pressures were adjusted to 30 to $32 \mathrm{~cm}$ of $\mathrm{H}_{2} 0$. Control group: Only had LMA cuff pressures monitored throughout the surgery. All patients were interviewed postoperatively at two, six and twelve hours. Data of their baseline characteristics, occurrence and severity of POST was collected. If POST was present; a Numerical Rating Scale (NRS) was used to assess the severity. Cuff pressures between the two study groups were also determined.

Results: The baseline demographic characteristics of the participants were similar. The use of manometry to limit LMA AMBUß AuraOnce ${ }^{\mathrm{TM}}$ intracuff pressure to $30-32 \mathrm{~cm} \mathrm{H}_{2} \mathrm{O}$ reduced POST in surgical patient's by $62 \%$ at 2 hours and 6 hours (Risk Ratio 0.38 95\% CI 0.21-0.69)in the intervention group. The median POST pain score in the intervention group was significantly lower than the control group with scores of 0 at 2, 6 and 12 hours post operatively. Routine practice of LMA cuff inflation by anesthesiologists is variable, and the intracuff pressures in the control group were higher than in the intervention group. $(\mathrm{P}<0.001)$

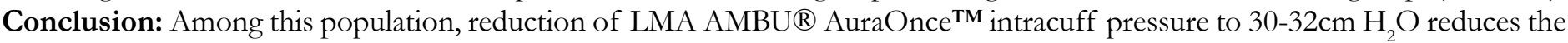
occurrence and severity of POST. The LMA cuff pressures should be measured routinely using manometry and reducing the intracuff pressures to $30-32 \mathrm{~cm}$ of $\mathrm{H}_{2} 0$ recommended as best practice.
\end{abstract}

Keywords: Laryngeal mask airway manometry, sore throat, surgery.

DOI: https://dx.doi.org/10.4314/ahs.v19i1.47

Cite as: Waruingi D, Mung'ayi V, Gisore E, Wanyonyi S. A randomised controlled trial of the effect of laryngeal mask airway manometry on postoperative sore throat in spontaneously breathing adult patients presenting for surgery at a university teaching hospital. Afri Health Sci. 2019;19(1). 1705-1715. bttps:// dx.doi. org/10.4314/ abs. v19i1.47

\section{Introduction}

\section{Corresponding author:}

Vitalis Mung'ayi,

Department of Anaesthesia,

Aga Khan University, East Africa

Phone: +254203662175

Email: mungayi@gmail.com
The Laryngeal Mask Airway (LMA) has been in use from 1981 since its invention by Dr Archie Brain, a British Anaesthesiologist ${ }^{1}$. In 2004 the Danish Medical Manufacturer launched a new disposable version of a Laryngeal Mask, the AMBU® AuraOnce ${ }^{\mathrm{TM}}{ }^{2}$. This is the commonest type of laryngeal mask used in Aga Khan University Hospital Nairobi. 
The LMA is less invasive than the tracheal tube and has proven to be a device that is simple to use, easy to teach and easy to learn. Studies in both adult and paediatric patients have detailed the ease of its use $\mathrm{e}^{3,4}$.

LMAs are widely used in surgery and are considered safe with minimal complications reported. ${ }^{6}$ They are considered better alternatives to the endotracheal tube in surgical patients. LMAs have been shown to have decreased anaesthetic requirements, decreased recovery times and earlier recovery times as compared to endotracheal tubes ${ }^{5}$. Adverse effects e.g. sore throat and aspiration following LMA airway use has been reported. There have been no reports of death attributable to the LMA airway in over 300 million uses of the device worldwide ${ }^{7}$. Rarer side effects following LMA use include hypoglossal nerve injury,lingual nerve injury,tongue cyanosis,macroglossia and vocal cord paralysis. They have been attributed to poor insertion techniques and excessive cuff pressure $2^{6}$.

As compared to the tracheal tube the incidence of postoperative sore throat (POST) during LMA use is lower 6 . However LMAs still cause POST. Dr Archie Brain, the inventor of the LMA first used it in 1983 to ventilate the lungs of 23 gynaecological patients. He titrated the cuff volume with $7 \mathrm{mls}$ of air to achieve a good seal and subsequently had little morbidity. Only three patients (13\%) had POST ${ }^{7,8}$.

Brimacombe and colleagues ${ }^{9}$ have reported the incidence of sore throat after LMA use to be as high as $42 \%$. Seet et $\mathrm{al}^{6}$ from North America recently demonstrated a reduction in occurrence of POST through use of LMA manometry from $45 \%$ to $13 \%$. The LMA they used however was the reusable classic type and the technique of insertion was not standardized. Bick et $\mathrm{al}^{8}$ from the United Kingdom have emphasized the need for LMA manometry and its importance in routine practice in their country. They have associated high LMA cuff pressures and POST, recurrent laryngeal nerve palsies, dysphagia and dysphonia.

Intraoperative manometry is not part of routine practice after insertion of LMAs in our hospital and in Kenya as a whole. This however can be detrimental since it has been shown that rough estimation of cuff pressures after insertion of an LMA may be harmful' ${ }^{2}$. It has also been shown that as many as $90 \%$ Clinicians are normally unaware of the high cuff pressures they use because of over reliance on manual methods of estimation ${ }^{10}$. Manufacturers recommendation for cuff volumes in the AMBU $\AA$ AuraOnce ${ }^{\text {TM }}$ LMA are $20 \mathrm{mls}$ for Size 3, 30mls for Size 4 and $40 \mathrm{mls}$ for Size $5^{15,11}$.Of the LMAs available, the AMBU® AuraOnce ${ }^{\mathrm{TM}}$ has been shown to produce very high oropharyngeal pressures ${ }^{11}$.This is of significance since it has been shown in repeated studies that when the laryngeal cuff is inflated with the recommended maximum volume of air, the intracuff pressure is normally two to three times the recommended value 16-18 High LMA intracuff pressures may reduce the pharyngeal mucosal perfusion and lead to throat discomfort ${ }^{15}$.

The reason the recommended volumes are high is based on the physical properties of the cuff. They are volumes to which an LMA can be distended without distorting the silicone, not a marker of what is suitable to patients ${ }^{8}$. There is more emphasis being placed in the healthcare field of how Clinicians need to reduce iatrogenic injuries during patient care. This is especially so in anaesthesiology because anaesthesia safety is the only system in healthcare that begins to approach the "six sigma" level of perfection ${ }^{16}$.

Despite being short-lived POST among patients is a large anaesthetic morbidity burden. It is ranked amongst the ten most common complaints by patients following surgery $^{17}$. It remains uncertain on the lowest possible LMA intracuff pressures that can be used while still maintaining an optimum seal for ventilation. By excluding other possible causes of POST this study sets out to investigate the role of LMA intraoperative manometry in alleviation of POST during LMA AMBU® AuraOnce ${ }^{\mathrm{TM}}$ use.

There is a paucity of local studies on LMAs and POST in our patient population. The aim of our study was to determine the effect of LMA cuff pressure manometry on occurrence of POST in spontaneously breathing adult surgical patients. Our study question was: does LMA cuff pressure manometry reduce the occurrence and severity of POST in spontaneously breathing adult patients undergoing surgery? 
We hypothesized that there is no difference in occurrence of POST in patients who have LMA cuff pressure adjustment and in those whom no LMA cuff pressure adjustment is done. Our primary objective was to compare the occurrence of POST between the intervention group in which LMA cuff pressures will be adjusted to 30 to $32 \mathrm{~cm}$ of $\mathrm{H}_{2} \mathrm{O}$ and the control group in which only monitoring of LMA cuff pressures will be done. Our secondary objectives were to compare the severity of POST between the two study groups and to compare the LMA cuff pressures between the two study groups.

\section{Methods}

This study commenced after ethical clearance from the Aga Khan University, Nairobi Research Ethics Committee. This was a prospective single blinded randomized control trial. The study was conducted at Aga Khan University Hospital, Nairobi; this is a tertiary not for profit hospital with a bed capacity of 240 beds and postgraduate medical education programs in various disciplines. Since Nairobi is a cosmopolitan city, the patients served by this hospital cut across most racial groups present within the country. Patients were recruited from the outpatient pre-anaesthesia clinics as well in-patients from the surgical wards. Study participants recruited into the study provided signed informed consent to participate in the study after a clear explanation of the study was provided during the pre-op assessment clinic. Participants were free to withdraw from the study at any time without affecting the quality of care that they received.

The sample population included all ASA I and II adult patients going to theatre for elective surgery between July 2015 and December 2015. This comprised all eligible patients scheduled for elective surgery that gave consent for the study

All elective surgical ASA I and II patients aged between 18-65 years who received general anaesthesia using an LMA were included in this study. These were patients undergoing gynaecological and obstetric surgery at less than 20 weeks gestation, general surgery of the peripheries including breast surgery, urological surgery or orthopaedic surgery lasting about one hour and where the patient could breathe spontaneously.

\section{Reasons for exclusion from the study were:}

a. History of ongoing upper respiratory tract infection. b. Patients with a failed LMA insertion defined as an unsuccessful LMA placement after two attempts.

c. Patients with severe gastro oesophageal reflux disease.

d. Patients with a symptomatic hiatus hernia.

e. Patients with a BMI $>40 \mathrm{~kg} / \mathrm{m}^{2}$.

f. Patients undergoing ENT-Ear Nose and Throat Procedures.

According to a study by Brimacombe and colleagues, the occurrence of POST was documented to be at $42 \%$ when patients had an LMA used without the use of cuff pressure monitoring ${ }^{9}$. The study was conducted in a comparable reference population as the one in this study. Seet and colleagues ${ }^{6}$ demonstrated a reduction in occurrence of POST from $45 \%$ to $13 \%$ with use of LMA manometry. This study thus hypothesized a $29 \%$ percent point reduction in the occurrence of POST in the intervention arm, where the LMA cuff pressures were monitored and adjusted throughout the surgical procedure.

The above sample size calculation yielded a sample size of 34 participants per arm. It was assumed that there would be a $20 \%$ loss to follow up. An adjustment to cater for loss to follow up was done (34*1.2). The sample size was therefore 40 participants per arm

A minimum sample size of 80 participants (40 in the intervention and 40 in the control arm) was found to be sufficient to estimate the difference in occurrence of POST in patients at AKUH with a 95\% confidence at a power of $80 \%$ and $\alpha=5 \%$.

Patients attending pre-op anesthesia clinic sessions were informed about the study and screened for eligibility. Patients who met the eligibility criteria received written informed consent to participate in the study by providing them with more details on the purpose and procedure of the study. Simple randomization was used. After obtaining informed consent, participants were randomly allocated to either arm. A total of 40 yellow stickers and 40 blue stickers were inserted in brown envelopes and sealed at the start of the study and mixed together. Each sticker represented an arm of the study; yellow represented the intervention arm and the blue sticker represented the control arm. Study participants were then requested to pick any envelops and unseal to reveal the sticker. The clinician then placed the stickers in the participants file for identification and administration of the procedures meant for the respective arms. 
Selection bias was controlled for by simple randomization. The investigating clinician was not privy to the details of the randomization process. The random allocation sequence was generated by a statistician. The color codes were placed in a sealed envelope, which was opened by the participants once they gave consent. The participants were also blinded from the arm that they were allocated to. This was done by allocating them to color coded study arms - in the consenting - as opposed to informing them that they have been allocated to either an intervention or control arm. The principal investigator - who implemented the intervention - was not involved in the phone follow up. The 2, 6 and 12 hour follow up was conducted by a research assistant who was not an anaesthesiologist. Participant flow diagram is shown in figure 1.

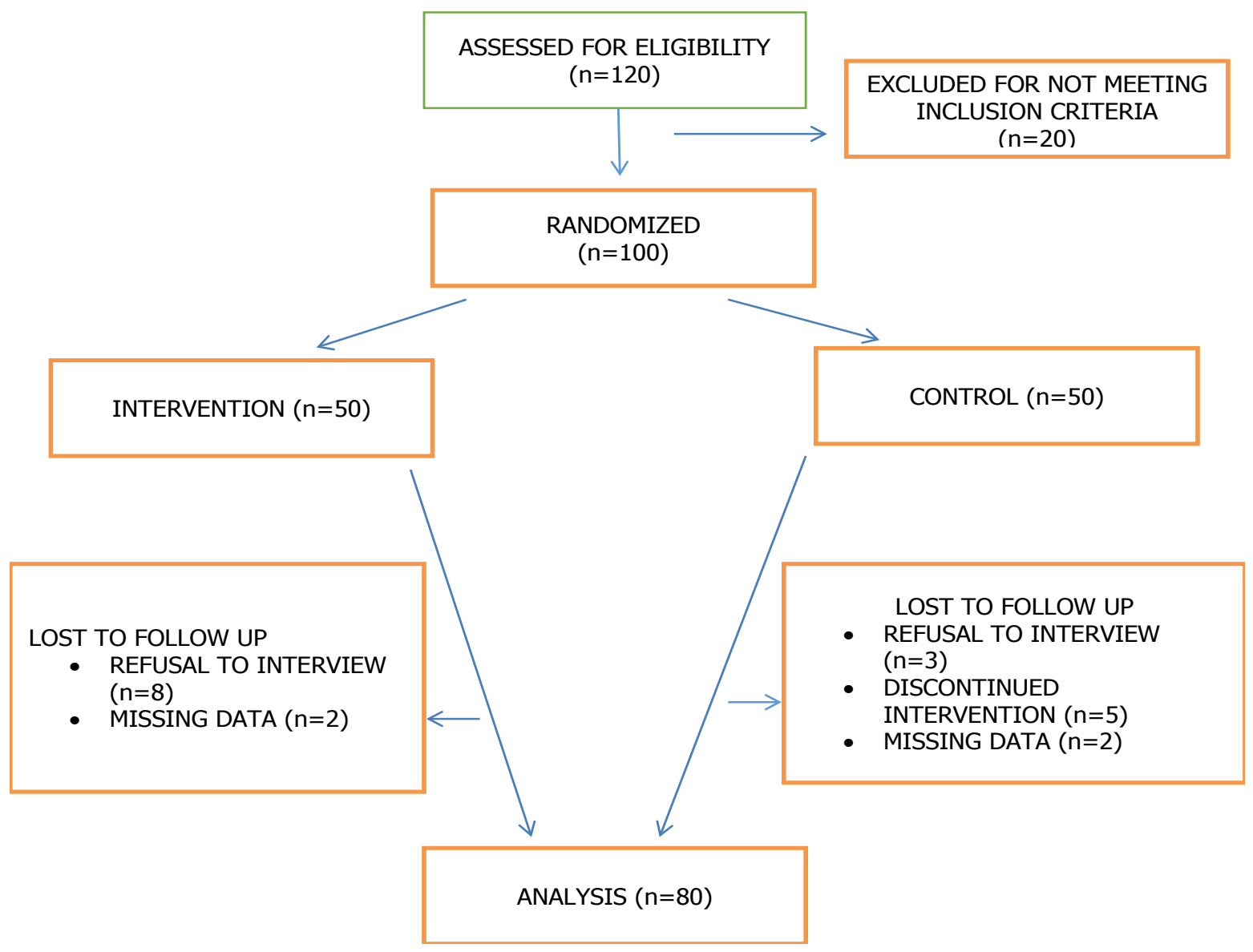

Figure 1- Flow diagram of patient distribution

Standard monitoring was applied to all patients and included non-invasive blood pressure measurement, electrocardiography and pulse-oximetry, with the objective of obtaining the baseline cardiovascular parameters. A standard protocol was used. Induction was achieved with intravenous fentanyl 1-2 micrograms per kilogram and intravenous propofol $2-3 \mathrm{mg} / \mathrm{kg}$. The patients then underwent manual ventilation with 100\% oxygen. Guedel type of airway was not used. The LMA Ambu® AuraOnce $^{\mathrm{TM}}$ was lubricated dorsally with a water-based lubricant (K-Y Lubricating jelly, Johnson and Johnson, Maidenhead, UK) before insertion.
The LMA was inserted when the depth of anaesthesia was judged to be appropriate (relaxation of the jaw and loss of eyelash reflex) according to the manufacturer's instructions ${ }^{8}$ by anaesthetists with more than 100 LMA insertions with this LMA type. A size 3 LMA was used for patients weighing between $30-50 \mathrm{kgs}$, a size 4 LMA for patients weighing $50-70 \mathrm{kgs}$ and a size 5 LMA for patients weighing between $70-100 \mathrm{kgs}$. A heat and moisture exchanger was used in all the cases and was attached to the proximal end of the LMA. If the LMA insertion was unsuccessful after two attempts the intervention was considered undelivered and the patient was withdrawn from the study. 
After the insertion of the LMA, assessment of ventilation was done by observation of capnography tracing and chest wall movement while delivering manual breaths where required. The LMA was repositioned if ventilation was not deemed adequate. The LMA cuff was inflated with a volume of air at the discretion of the attending anaesthesiologist. General anaesthesia was maintained with isoflurane (1-1.3\% minimum alveolar concentration) in an air-oxygen mixture via a circle breathing system. Nitrous oxide was not used.

Once regular spontaneous breathing was achieved, the principal investigator then measured the LMA intracuff pressure using a handheld airway pressure manometer, (HI-LO Hand pressure gauge ${ }^{\mathrm{TM}}$ Covidien $\left.{ }^{\circledR}\right)$. This manometer was calibrated by the engineering department and tested for leaks before the study and once a month during the study. In the intervention group, the principal investigator deflated the LMA intracuff pressure to a value of 30 to $32 \mathrm{~cm}$ of $\mathrm{H}_{2} \mathrm{O}$ and recorded the intracuff pressures every five minutes until the end of surgery. In the control group, the LMA intracuff pressure was noted and no further action taken and similarly recorded every five minutes until the end of surgery. The manometer was turned away from the sight of the attending anaesthesiologist. The attending anaesthesiologist was blinded to the group assignment and to the LMA intracuff pressure.

Intraoperatively, intravenous paracetamol $15 \mathrm{mg} / \mathrm{kg}$ and pethidine $1 \mathrm{mg} / \mathrm{kg}$ were titrated for analgesia according to patient requirements. NSAIDs were not given. At the end of surgery, the anaesthesiologist removed the LMA when the patient was fully awake and able to open their mouth on verbal command. The LMA cuff was not deflated for removal. Pharyngeal suctioning was not performed. The patients were monitored in the post-anaesthesia care unit and subsequently discharged to the daycare surgical unit and surgical wards.

Intra-operative data was collected by the principal investigator using a data collection form. Data on the presence or absence of POST and its severity was collected by a research assistant using a structured questionnaire at 2 , 6 and 12 hours post-operatively. The collected data was counterchecked for complete entry by the principal investigator and keyed into an MS Excel database. All paper forms with raw data were filed in suitable box files which were kept locked in the investigator's locker. All sheets were checked for completeness prior to filing. Computers used to enter data were password protected at the operating system level using software that is commercially available. Data keyed into the MS excel database was imported into the Statistical Package for Social Sciences (SPSS) program, version 11.5 (SPSS Inc, Chicago, IL, USA). Data analysis was performed using the same software.

Continuous variables such as age, BMI, size of LMA, cuff pressure were summarized as means and presented in table form. Categorical variables such as occurrence of POST, gender, reasons for surgery, level of attending anaesthesiologist were presented as proportions in tables. Occurrence of POST in both study arms was presented as a proportion and reported together with the 95\% confidence interval. The difference in severity of POST in both arms was analyzed using the Mann-Whitney $\mathrm{U}$ test. The association between occurrence of POST and sex, type of surgery, level of attending anaesthesiologist , number of attempts of insertion, use of guedels airway and use of pharyngeal suctioning was determined using the Pearson Chi Square test. A p value of $<0.05$ was considered statistically significant. The difference in means of cuff pressures in the study arms was analyzed using the Student t-test. In the event that the cuff pressures did not meet the rules of normality, the Mann-Whitney non-parametric test was applied. A p value of $<0.05$ was considered statistically significant

\section{Results}

A total of 80 participants were recruited into the study 40 participants per arm. Baseline characteristics of age, ASA status, sex distribution, weight and number of attempts of LMA insertion for the patients in the two study arms were similar as shown in table 1 . 
Table 1: Patient and clinical characteristics

\begin{tabular}{|l|l|l|}
\hline & Intervention group n=40 & Control group n=40 \\
\hline Age (Years) & $33[29.4,36.6]$ & 35 years [32.6,37.3] \\
\hline ASA & $1(1,2)$ & $1(1,2)$ \\
\hline Sex & & \\
Male & $17(42.5 \%)$ & $26(65 \%)$ \\
$\quad$ Female & $23(57.5 \%)$ & $14(35 \%)$ \\
\hline Weight (Kilograms) & $70 \mathrm{~kg}[67.2,72.7]$ & $73 \mathrm{~kg}[70.4,75.7]$ \\
\hline Number of insertion attempts & \multicolumn{2}{|l|}{} \\
One & $26(65 \%)$ & $32(80 \%)$ \\
$\quad$ Two & $14(35 \%)$ & $8(20 \%)$ \\
\hline Mean age and weight are presented as means + /- SD. \\
ASA is presented as a median (min, max) \\
All other variables are presented as n (\%) \\
\hline \multicolumn{2}{|l}{} \\
\hline
\end{tabular}

The same size of LMA (size 4) was used for all participants in both arms. Participants in the intervention arm had significantly lower overall occurrence of POST compared to the controls ( $25 \%$ versus $65 \%$ RR 0.38 CI $95 \%$ with $\mathrm{p}<0.001)$. This trend was seen consistently at 2,6 and 12 hours post-operatively. This is illustrated in table 2 . There was a significantly higher median pain score of POST in the control arm at 2, 6 and 12 hours with difference in median values of 7,6 and 5.5 respectively com- pared to the intervention arm with $\mathrm{p}<0.001$ as shown in table 3 . The median score in the intervention arm was zero at all three evaluations. Median pain score however decreased with time in the control group. As illustrated in table 4 cuff pressure in the control arm was significantly higher ranging between 49 and $56 \mathrm{~cm} \mathrm{H}_{2} \mathrm{O}$ compared to the intervention arm, which ranged between 30 and $31 \mathrm{~cm} \mathrm{H}_{2} \mathrm{O}$. None of the participants had cuff pressure readings beyond 60 and 90 minutes in the control and intervention groups respectively. 
Table 2: Comparison of occurrence of POST in the Intervention group and control group

\begin{tabular}{|c|c|c|c|c|}
\hline & $\begin{array}{l}\text { Intervention } \\
\text { group }\end{array}$ & $\begin{array}{l}\text { Control } \\
\text { group }\end{array}$ & $\begin{array}{l}\text { Relative } \\
\text { Risk }\end{array}$ & *P value \\
\hline $\begin{array}{l}\text { Post operative } \\
\text { sore throat } \\
\text { Overall } \\
\text { proportion } \\
{[95 \% \mathrm{CI}]}\end{array}$ & $\begin{array}{r}10 \\
25 \%[11.6,38.4]\end{array}$ & $\begin{array}{r}26 \\
65 \%[50.2,79.8]\end{array}$ & $\begin{array}{r}0.38 \\
(0.21-0.69)\end{array}$ & $<0.001$ \\
\hline $\begin{array}{l}\text { Post-operative } \\
\text { sore throat } \\
2 \text { hours } \\
\text { Proportion } \\
{[95 \% \mathrm{CI}]}\end{array}$ & $\begin{array}{r}10 \\
25 \%[11.6,38.4]\end{array}$ & $\begin{array}{r}26 \\
65 \%[50.2,79.8]\end{array}$ & $\begin{array}{r}0.38 \\
(0.21-0.69)\end{array}$ & $<0.001$ \\
\hline $\begin{array}{l}\text { Post-operative } \\
\text { sore throat } \\
6 \text { hours } \\
\text { Proportion } \\
{[95 \% \mathrm{CI}]}\end{array}$ & $\begin{array}{r}10 \\
25 \%[11.6,38.4]\end{array}$ & $\begin{array}{r}26 \\
65 \%[50.2,79.8]\end{array}$ & $\begin{array}{r}0.38 \\
(0.21-0.69)\end{array}$ & $<0.001$ \\
\hline $\begin{array}{l}\text { Post-operative } \\
\text { sore throat } \\
12 \text { hours } \\
\text { Proportion } \\
{[95 \% \text { CI] }}\end{array}$ & $\begin{array}{r}12 \\
30 \%[15.8,44.2]\end{array}$ & 26 & $\begin{array}{r}0.46 \\
(0.27-0.78)\end{array}$ & 0.002 \\
\hline
\end{tabular}

- Two sample test of proportion was applied to check for any significant differences POST between the two arms

- $\quad * \mathrm{P}$ value for two sample test of proportion

- Missing data were omitted from the analysis

- The Relative risk with 95\% Confidence Interval 
Table 3: Differences in severity of POST in both study arms.

\begin{tabular}{|l|c|c|c|c|c|}
\hline & $\mathbf{n}$ & $\begin{array}{l}\text { Intervention arm } \\
\text { Median (range) }\end{array}$ & $\begin{array}{l}\text { Control arm } \\
\text { Median (range) }\end{array}$ & $\begin{array}{l}\text { Difference } \\
\text { in medians }\end{array}$ & P value \\
\hline $\begin{array}{l}\text { Median POST } \\
\text { Severity - 2 hours }\end{array}$ & 40 & $0(0$ to 8$)$ & $7(0$ to 9$)$ & 7 & $<0.001$ \\
\hline $\begin{array}{l}\text { Median POST } \\
\text { Severity - 6 hours }\end{array}$ & 40 & $0(0$ to 7$)$ & $6(0$ to 8$)$ & 6 & $<0.001$ \\
\hline $\begin{array}{l}\text { Median POST } \\
\text { Severity-12 hours }\end{array}$ & 40 & $0(0$ to 6$)$ & $5.5(0$ to 8$)$ & 5.5 & $<0.001$ \\
\hline
\end{tabular}

- The Mann-Whitney U test was used to determine the difference in the medians of the severity scores between the two arms.

- Missing data were omitted from the analysis.

- P value of less than 0.05 was deemed statistically significant.

Table 4: Cuff pressures

\begin{tabular}{|r|c|c|c|}
\hline & Intervention group & Control group & \multirow{2}{*}{ P value } \\
\hline \multirow{2}{*}{ Time Points } & $\begin{array}{c}\mathbf{n} \\
\text { Mean pressure(95\%CI) }\end{array}$ & Mean pressure (95\%CI) & \\
\hline \multirow{2}{*}{5 minutes } & 40 & 40 & \multirow{2}{*}{$<0.001$} \\
\cline { 2 - 3 } & $30.5(30.4,30.7)$ & $50.3(46.0,54.7)$ & \multirow{2}{*}{$<0.001$} \\
\hline \multirow{2}{*}{15 minutes } & 40 & 40 & $<0.001$ \\
\cline { 2 - 3 } & $30.5(30.4,30.7)$ & $50.2(46.0,54.3)$ & $<0.001$ \\
\hline \multirow{2}{*}{30 minutes } & 40 & $49.3(45.7,52.9)$ & \multirow{2}{*}{$<0.001$} \\
\cline { 2 - 3 } & $30.5(30.4,30.7)$ & 18 & $<0.001$ \\
\hline
\end{tabular}

- The two-sample t test was applied to test for differences in the mean cuff pressure readings

- $\quad$ Missing data were omitted from the analysis

- $\quad$ P value of less than 0.05 was statistically significant

\section{Discussion}

This study demonstrates that the use of manometry to limit LMA AMBU ${ }^{\circledR}$ AuraOnce ${ }^{\mathrm{TM}}$ intracuff pressure to $30-32 \mathrm{~cm}$ of $\mathrm{H}_{2} 0$ reduces POST in surgical patients by $62 \%$ at 2 hours and 6 hours and by $54 \%$ at 12 hours. Secondly, the median POST pain score was 0 at 2, 6 and
12 hours post-operatively in the intervention group. The median POST pain score was higher in the control group and ranged between 5 and 7 . Thirdly, routine practice of LMA cuff inflation by anesthesiologists is varied, and the intracuff pressure in the control group was higher than in the intervention group. 
High intracuff pressure in an LMA impedes pharyngeal mucosal perfusion, and this may lead to pharyngolaryngeal complications ${ }^{19}$. However, there are contradictory findings in the literature. Brimacombe and colleagues9 showed in a randomized controlled trial that inflation of the LMA cuff with a smaller volume of air $(15-20 \mathrm{ml})$ was associated with a decreased incidence of the primary outcome of sore throat at 18-24 h post-operatively (20 vs. $42 \%, \mathrm{P}<0.04)$ compared with a larger volume of air $(30-40 \mathrm{ml})$. The occurrence of POST in our intervention group was significantly less at $25 \%$ at 2 and 6 hours. In the study by Brimacombe, nitrous oxide was part of the anaesthetic. Nitrous oxide may have increased intracuff pressure over time. The LMA intracuff pressure was also not measured?.

Kang and colleagues 20 showed in a prospective randomized trial that limiting the intracuff pressure in the LMA Supreme reduced post operative pharyngolaryngeal events in the first and the second post-operative day. These data suggest that pressures significantly lower than $60 \mathrm{~cm}$ of $\mathrm{H}_{2} \mathrm{O}$ may be preferable. A recent systematic review by El-Boghdadly and colleagues ${ }^{21}$ suggests that limiting LMA intracuff pressure to less than $60 \mathrm{~cm}$ of water $(44 \mathrm{mmHg})$ may be a potential risk reduction intervention for POST.

Rieger and colleagues ${ }^{22}$ did a randomized trial involving seventy patients. Some patients were randomly allocated to either high LMA intra-cuff pressures of $240 \mathrm{~cm}$ of $\mathrm{H}_{2} 0$ or to low LMA intra-cuff pressures of $40 \mathrm{~cm}$ of $\mathrm{H}_{2} 0$.The laryngopharyngeal complaints (sore throat, dysphagia, and hoarseness) were then evaluated. The study found no differences in occurrence of sore throat between the two study groups. They concluded that intra-cuff pressures have no effect in alleviation of POST. Anaesthesia was maintained with enflurane in nitrous oxide and oxygen. The use of nitrous oxide may have been a possible confounder.

Karthik and colleagues ${ }^{23}$ did a randomized controlled trial comparing high and low volume cuff pressures in the ProSeal LMA. Some patients were allocated to LMA pressures of below $60 \mathrm{~cm}$ of water and in the control group LMA intracuff pressures were noted and no further action taken. They found no statistically significant differences in the incidence of pharyngolaryngeal complications by limiting intracuff pressures in the ProSeal LMA.

The uniqueness of this study is that it specifically investigates the usefulness of manometry to aid modern day practice of general anesthesia using the LMA AMBUß AuraOnce ${ }^{\mathrm{TM}}$ The previous trials investigated different LMA types like Classic and ProSeal.

General anesthesia in patients who underwent surgery was induced with intravenous propofol and maintained with isoflurane in air-oxygen mixture with no nitrous oxide. The previous randomized controlled trials reflected different anesthetic practices with the use of nitrous oxide, which may cause an increase in intracuff pressure over time. This study also took into account potential known confounders for POST during LMA use. The LMA insertion attempts were limited to two attempts, no pharyngeal suctioning was done, a water based lubricant was used and the anaesthesia protocol was standardized.

Direct questioning was employed in this study as opposed to previous studies. The mode of questioning is an important determinant of the occurrence of POST. By questioning indirectly, patients concentrate on symptoms related to the operative site and do not immediately associate POST with anaesthesia and surgery ${ }^{18}$.

One of the study limitations is that the insertion technique was not standardized because of varied individual preferences. Anaesthesiologists used their preferred technique of insertion. In AKUH, N majority insert the LMA partially inflated. It is not clear whether the LMA insertion technique affects the incidence of POST. There are contradictory findings in the literature with proponents ${ }^{24}$ and opponents ${ }^{25}$. Secondly, this study failed to show any impact of manometry and intracuff pressure limitation on nerve injuries associated with LMA use. These occurrences are extremely rare and would require a much larger sample size to detect a difference and a long duration of time. The sex differences between the control and intervention group seems to be clinically significant. These statistical significances could influence the outcome of the study despite it being a result of chance from the process of randomization and clinically may be of value. 


\section{Conclusion}

There was benefit from the use of manometry after the insertion of the LMA AMBU® AuraOnce ${ }^{\mathrm{TM}}$ by reducing POST by $62 \%$. Based on findings of this study, it would seem beneficial forLMA AMBU® AuraOnce ${ }^{\text {TM }}$ cuff pressure to be measured routinely using manometry, and deflating the cuff to less than manufacturer's recommendations of $60 \mathrm{~cm}$ of water to $30 \mathrm{~cm}$ of water.

\section{Trial registration}

PACTR201511001336196

\section{Research Ethics Committee reference 2015/REC-12(v3)}

\section{Conflict of interest}

All the authors declare no conflict of interest.

\section{References}

1. Brain AJ. The Laryngeal Mask-A New Concept In Airway Management. Br J Anaesth. 1983 Aug; 55(8):801-5.

2. Hernandez MR, Klock PA, Ovassapian A. Evolution of the extraglottic airway: A review of its history, applications, and practical tips for success. Anesth Analg. 2012 Feb;114(2):349-68.

3. Verghese C, Brimacombe JR. Survey of laryngeal mask airway usage in 11,910 patients:safety and efficacy of conventional and nonconventional usage. Anesth Analg. 1996 Jan;82(1):129-33

4. Mason DG, Bingham RM. The laryngeal mask airway in children. Anaesthesia. 1990 Sep;45(9):760-3.

5. Joshi GP, Inagaki Y, White PF, Taylor-Kennedy L, Wat LI, Gevirtz C, et al. Use of the laryngeal mask airway as an alternative to the tracheal tube during ambulatoryanesthesia. Anesth Analg. 1997 Sept ;85(3):573-7.

6. Seet E, Yousaf F, Gupta S, Subramanyam R, Wong DT, Chung F. Use of manometry for laryngeal mask airway reduces postoperative pharyngolaryngeal adverse events: a prospective, randomized trial. Anesthesiology. 2010 Mar;112(3):652-7.

7. Van Zundert TC, Brimacombe JR, Ferson DZ, Bacon DR, Wilkinson DJ. Archie Brain: Celebrating 30 years of development in laryngeal mask airways. Anaesthesia. 2012 Dec;67(12):1375-85.

8. Bick E, Bailes I, Patel A, Brain AI. Fewer sore throats and a better seal:why routine manometry for laryngeal mask airways must become the standard of care. Anaesthesia. 2014 Dec ;69(12):1304-8.
9. Brimacombe J, Holyoake L, Keller C, Brimacombe N, Scully M, Barry J, et al. Pharyngolaryngeal, neck, and jaw discomfort after anesthesia with the face mask and laryngeal mask airway at high and low cuff volumes in males and females. Anesthesiology. 2000 Jul;93(1):26-31.

10. Braz JR, Navarro LH, Takata IH, Nascimento Júnior P. Endotracheal tube cuff pressure: need for precise measurement. Sao Paulo Med J. 1999 Nov 4;117(6):243-7.

11. Williams DL, Zeng JM, Alexander KD, Andrews DT. Randomised comparison of the AMBU AuraOnce laryngeal mask and the LMA unique laryngeal mask airway in spontaneously breathing adults. Anesthesiol Res Pract. 2012;2012:405812

12. Asai T, Howell TK, Koga K, Morris S. Appropriate size and inflation of the laryngeal mask airway. $\mathrm{Br} J \mathrm{An}$ aesth. 1998 Apr;80(4):470-4.

13. Keller C, Brimacombe J. Mucosal pressure and oropharyngeal leak pressure with the ProSeal versuslaryngeal mask airway in anaesthetized paralysed patients. $\mathrm{Br} J \mathrm{An}$ aesth. 2000 Aug;85(2):262-6.

14. Burgard G, Möllhoff T, Prien T. The effect of laryngeal mask cuff pressure on post operative sore throat incidence. J Clin Anesth. 1996 May;8(3):198-201.

15. O'Kelly SW,Heath KJ, Lawes EG. A study of laryngeal mask inflation. Pressures exerted on the pharynx. Anaesthesia. 1993 Dec;48(12):1075-8.

16. Leape LL, Berwick DM, Bates DW. What practices will most improve safety? Evidence-based medicine meets patient safety. JAMA. 2002;288(4):501-7.

17. Macario a, Weinger M, Carney S, Kim a. Which clinical anesthesia outcomes are important to avoid? The perspective of patients. Anesth Analg. 1999 Sep;89(3):652-8. 18. Harding C, McVey FK. Interview method affects incidence of postoperative sore throat. Anaesthesia. 1987 Oct;42(10):1104-7.

19. Marjot R. Pressure exerted by the laryngeal mask airway cuff upon the pharyngeal mucosa. BrJ Anaesth. 1993 Jan;70(1):25-9.

20. Kang JE, Oh CS, Choi JW, Son IS, Kim SH. Postoperative pharyngolaryngeal adverse events with laryngeal mask airway (LMA Supreme) in laparoscopic surgical procedures with cuff pressure limiting $25 \mathrm{~cm} \mathrm{H} 2 \mathrm{O}$ : Prospective, blind, and randomised study. Scientific World Journal. 2014 Mar 17;2014:709801

21. El-Boghdadly K, Bailey CR, Wiles MD. Postoperative sore throat: a systematic review. Anaesthesia. 2016 Jun;71(6):706-17

22. Rieger A, Brunne B, Striebel HW. Intracuff pres- 
sures do not predict laryngopharyngeal discomfort after use of the laryngeal mask airway. Anesthesiology. 1997 Jul;87(1):63-7.

23. Vasanth Karthik R, Ranganathan P, Kulkarni AP, Sharma KS. Does cuff pressure monitoring reduce postoperative pharyngolaryngeal adverse events after LMA-ProSeal insertion? A parallel group randomised trial. J Anesth. 2014 Oct;28(5):662-7.
24. Wakeling HG, Butler PJ, Baxter PJ. The laryngeal mask airway: a comparison between two insertion techniques. Anesth Analg. 1997 Sep;85 (3):687-90.

25. Choo CY, Koay CK, Yoong CS. A randomised controlled trial comparing two insertion techniques for the laryngeal mask airway FlexibleTM in patients undergoing dental surgery. Anaesthesia. 2012 Sep;67(9):986-90. 